\title{
MEASUREMENT OF THE EFFECT ON THE PAIN THRESHOLD OF ACETYLSALICYLIC ACID, ACETANILID, ACETOPHENETIDIN, AMINOPYRINE, ETHYL ALCOHOL, TRICHLORETHYLENE, A BARBITURATE, QUININE, ERGOTAMINE TARTRATE AND CAFFEINE: AN ANALYSIS OF THEIR RELA- TION TO THE PAIN EXPERIENCE
}

\author{
By H. G. WOLFF, J. D. HARDY, AND H. GOODELL \\ (From the Russell Sage Institute of Pathology in Affliation with the New York Hospital, and \\ the Departments of Medicine and Psychiatry, Cornell University Medical College, New York)
}

(Received for publication August 27, 1940)

Analysis of the analgesia induced by the opiates has shown that these agents are capable not only of greater pain threshold-raising action than all other substances investigated, but also of important effects on the reaction to pain (1). Although the action of the non-opiate analgesics has been explored (2 to 20), the evidence hitherto presented is conflicting, often because the data have been non-quantitative, inadequate, or irrelevant. The development of a new method (21) for assaying quantitatively the effects of analgesic agents on man has made possible the following presentation of new data concerning the nonopiate analgesics.

\section{METHOD}

The method employed here was described in detail in earlier studies on pain and analgesia (21). The light from a 1000 watt lamp was focussed by a condensing lens through a fixed aperture onto the blackened forehead of the subject. The surface of the forehead to be tested was thoroughly blackened with India ink. The intensity of the radiation was controlled by means of a rheostat. Immediately in front of the lamp was mounted an automatic shutter which was arranged to allow the radiation to pass through to the subject for exactly 3 seconds. The method of making the measurement of pain threshold was as follows: The subject seated himself and placed his forehead in position. The aperture was arranged so that $3.5 \mathrm{~cm}^{2}$ of blackened skin could be exposed. After a minute or so the shutter was lowered and the radiation allowed to fall on the skin for 3 seconds. The subject reported on his sensation. If no pain was experienced, the intensity of the light was increased and after 30 to 60 seconds the test was repeated. This procedure was followed until the subject just felt pain at the end of the exposure. This threshold pain was easily recognizable even by untrained subjects. The sensation was that of heat finally "swelling" to a distinct, sharp stab of pain at the end. When this condition had been reached the radiometer was placed in the aperture in place of the forehead of the subject and the intensity of the radiation measured in $\mathrm{gm}$. cal./sec./cm. ${ }^{2}$ This value was considered to be the minimum stimulus for pain. The time required to make a single observation was usually less than 2 minutes. The maximum variation from the mean was in all cases less than 12 per cent, and several measurements agreeing within 2 per cent were made to establish a threshold.

After the control measurements, an analgesic agent was administered and observations of the pain threshold were made at 10 to 20 -minute intervals until the threshold had returned to the control level. The height of the pain threshold-raising effect was expressed in per cent elevation above the control level. The protocols were distributed so that the threshold of one subject was measured by another subject who in turn was unfamiliar with the change in his own threshold. Occasionally, observers not participants in the experiment made threshold readings. Thus, three independent protocols were made, no individual knowing how much his own threshold had been altered.

With each pain threshold reading the subject made a concise statement of his psychological state. In the 10minute interims between readings the subjects sat comfortably and engaged in reading, writing, or conversation. Sleep was not permitted and, if drowsy, the subjects walked about the laboratory. During long experiments food was taken, the three subjects consuming about the same amount of milk and bread. This required less than 15 minutes, after which the readings were continued.

In this series, all agents were given by mouth, with the exception of trichlorethylene, which was inhaled, and ergotamine and caffeine, which were injected intramuscularly. Therefore, the onset of action and the percentage increase in threshold and duration of action were variable. The subjects were, as in the earlier experiments, the three authors, each of whom weighed approximately 65 kilos.

The time-action curves for all agents in the amount given, were analyzed in three ways: (1) The maximum height of the pain threshold-raising effect; (2) the length of the period of effectiveness, and (3) the total thresholdraising action of the agent.

The maximum height of the threshold-raising action was obtained from the highest part of each time-action curve. The length of the effective period was taken to be the elapsed time between the administration of the 


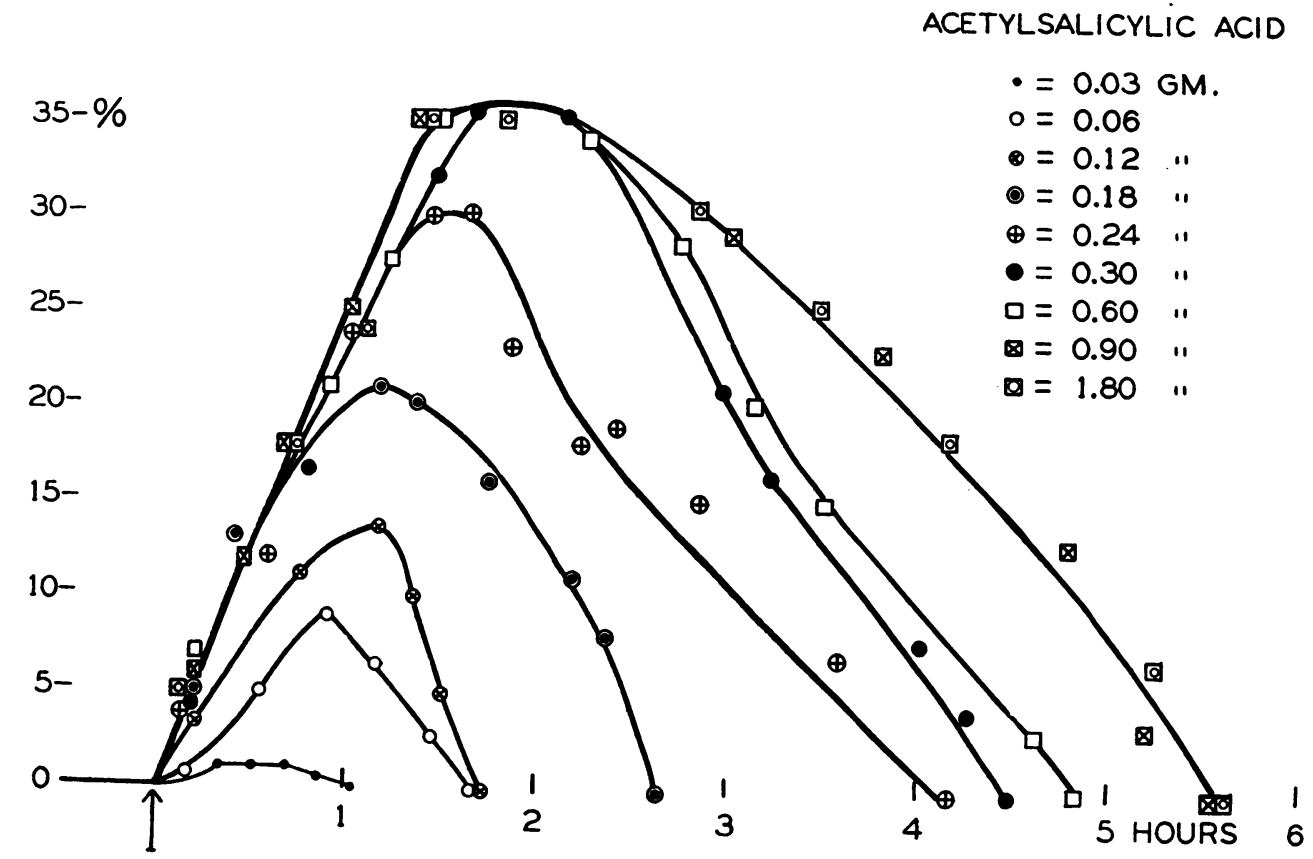

Fig. 1. Time-Action Curves for Acetylsalicylic Actd

The ordinate $=$ per cent elevation of pain threshold over the control level as zero. The abscissa = duration of effect. The arrow indicates the time of ingestion of the acetylsalicylic acid. Each point represents the average of the threshold levels of two or three subjects.

agent and the return of the threshold to the pre-administration level. The total threshold-raising action was computed by multiplying the duration in hours of effect by the average per cent above the control level.

\section{Acetylsalicylic acid}

Observations. Twenty-four experiments were done with amounts from 0.03 gram to 1.8 grams of acetylsalicylic acid. There were at least two participants in each experiment and a total of 54 series of observations was made. The time-action curves for the nine different amounts studied were of a simple type (Figure 1).

The height and duration of the threshold-raising effect increased with the amount administered from 0.06 gram to 0.3 gram. Whether the amount of the agent was large or small the pain threshold was observed to rise within 10 to 15 minutes of ingestion and continued to rise at different rates until the peak effect for the particular amount had been reached.

Comment. It will be seen (Figure 2) that the maximum analgesic effect is directly proportional to quantities from 0.06 gram to 0.3 gram but is not increased with greater amounts. Further threshold-raising effects might be obtained with very large quantities of this agent, but these are beyond the scope of this study.

The duration of the threshold-raising effect increased with the amount given from 0.06 gram to 0.9 gram (Figure 3), but the rate of increase became progressively smaller.

The relation of total threshold-raising action to amount is shown in Figure 4. There was an increase in effect with the amount up to 0.3 gram. With each additional 0.3 gram from 0.3 to 0.9 gram there was an increase of about 10 per cent, but doubling 0.9 gram, or 1.8 grams, increased the effect only slightly.

Observation. The time-action curves (Figure 1) indicate that the total threshold-raising effect realized from a given amount of acetylsalicylic acid will depend upon the frequency of dosage. Acetylsalicylic acid in 0.3 gram amounts was administered orally at 2 -hour intervals over a period of 8 hours. The readings recorded at 10- to 20minute intervals throughout this period show that, following the first 0.3 gram amount, the threshold was raised to the usual level, after which the pain threshold remained elevated for about 6 hours 


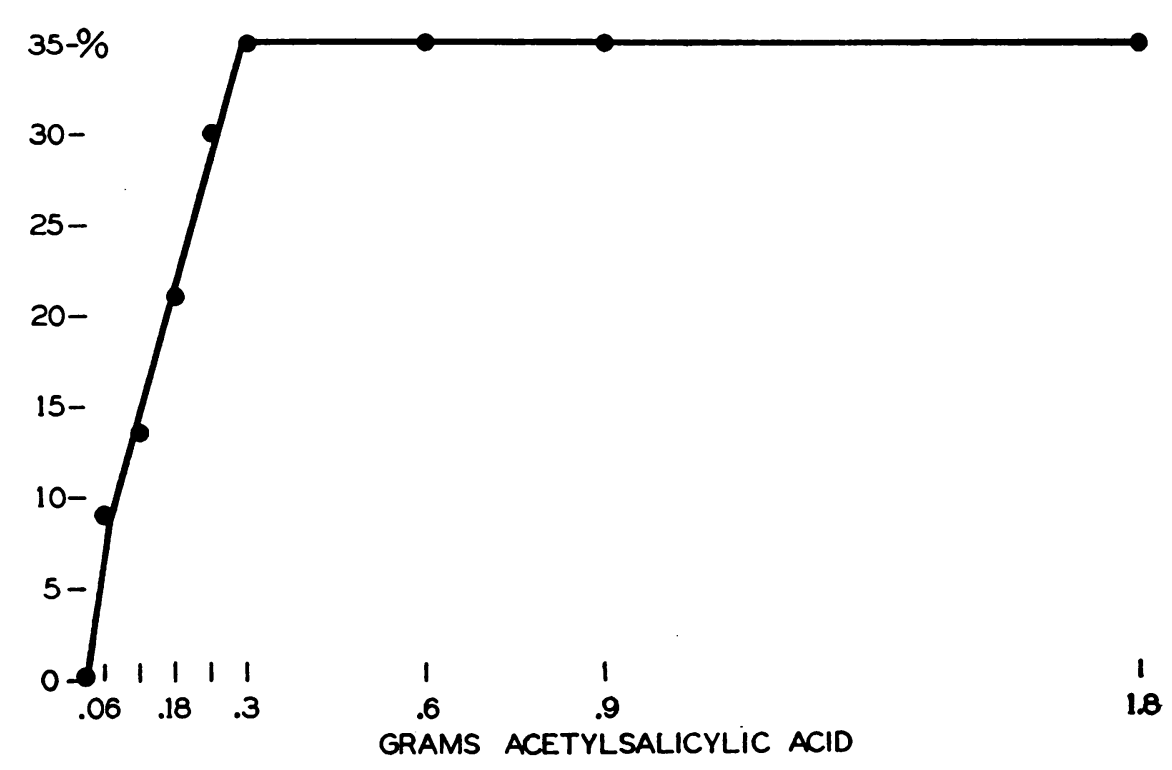

Fig. 2. The Maximum Pain Threshold-Raising Effect of Acetylsalicylic Acid for Quantities from 0.06 Gram to 1.8 Grams

DURATION OF THRESHOLD RAISING EFFECT

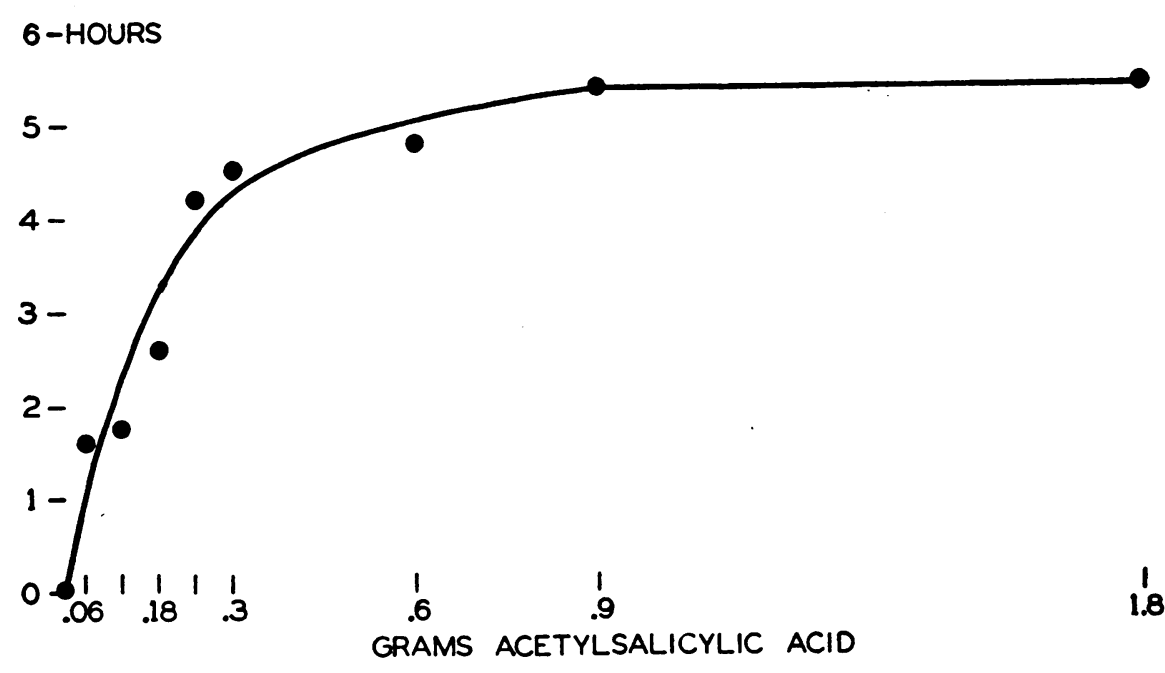

Fig. 3. The Relation Between Duration of Threshold-raising Effect (Ordinate) and the Quantity of AcEtylsalicylic Acid Administered (Abscissa)

at 30 to 35 per cent above the control level (Figure 5).

In contrast 0.6 gram of acetylsalicylic acid given three times at intervals of 3 hours resulted in unstable elevation of the pain threshold (Figure 6).

Comment. Comparison of Figures 5 and 6 demonstrates that 1.2 grams of acetylsalicylic acid administered in amounts of 0.3 gram every 2 hours produce at least a third more threshold-raising effect in 8 hours than 1.8 grams administered in amounts of 0.6 gram every 3 hours. From the standpoint of therapy, these experiments indicate that it is desirable to give frequent administra- 


\section{0-HOURS PERCENT}

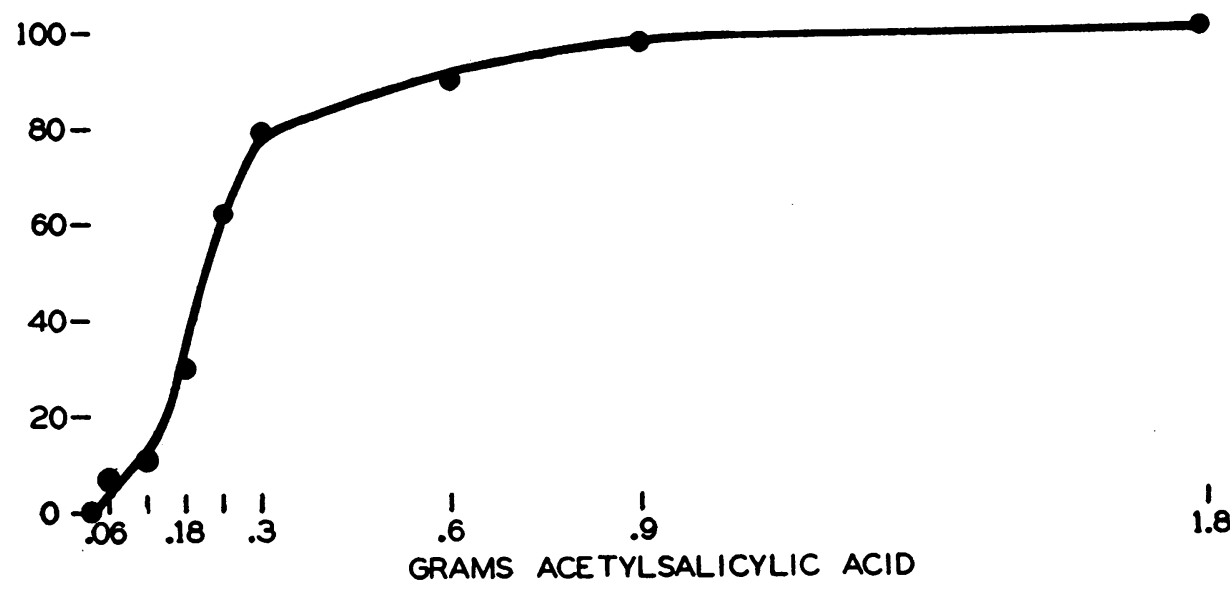

Fig. 4. The Relation Between the Total Threshold-raising Empect and the Quantity of AcEtylsalicylic Acid Administered

The ordinate was computed by multiplying the average per cent rise in pain threshold by the hours of duration of effect resulting from a given quantity of acetylsalicylic acid. The abscissa = quantity of acetylsalicylic acid administered.

\section{REPEATED ADMINISTRATIONSS OF ACETYLSALICYLIC ACID 0.3 GM.}

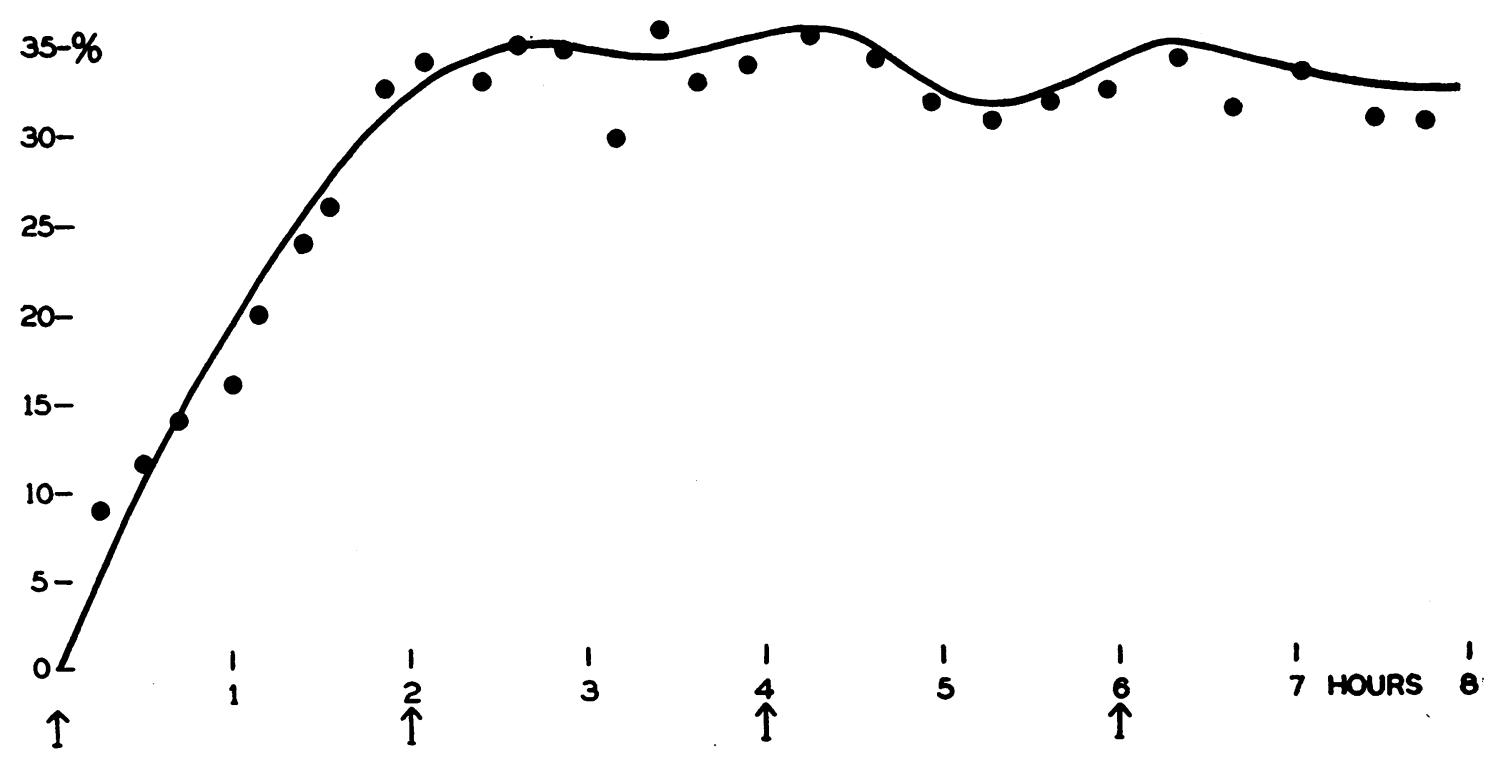

Fig. 5. The Efrect on the Pain Threshold of Repeated Ingestions of Acetylsalicylic Actd 0.3 Gram at 2-HOUR Intervals

Each point represents the average of the threshold levels of two subjects. 
REPEATED ADMINISTRATIONS OF

ACETYLSALICYLIC ACID

0.6 GM.

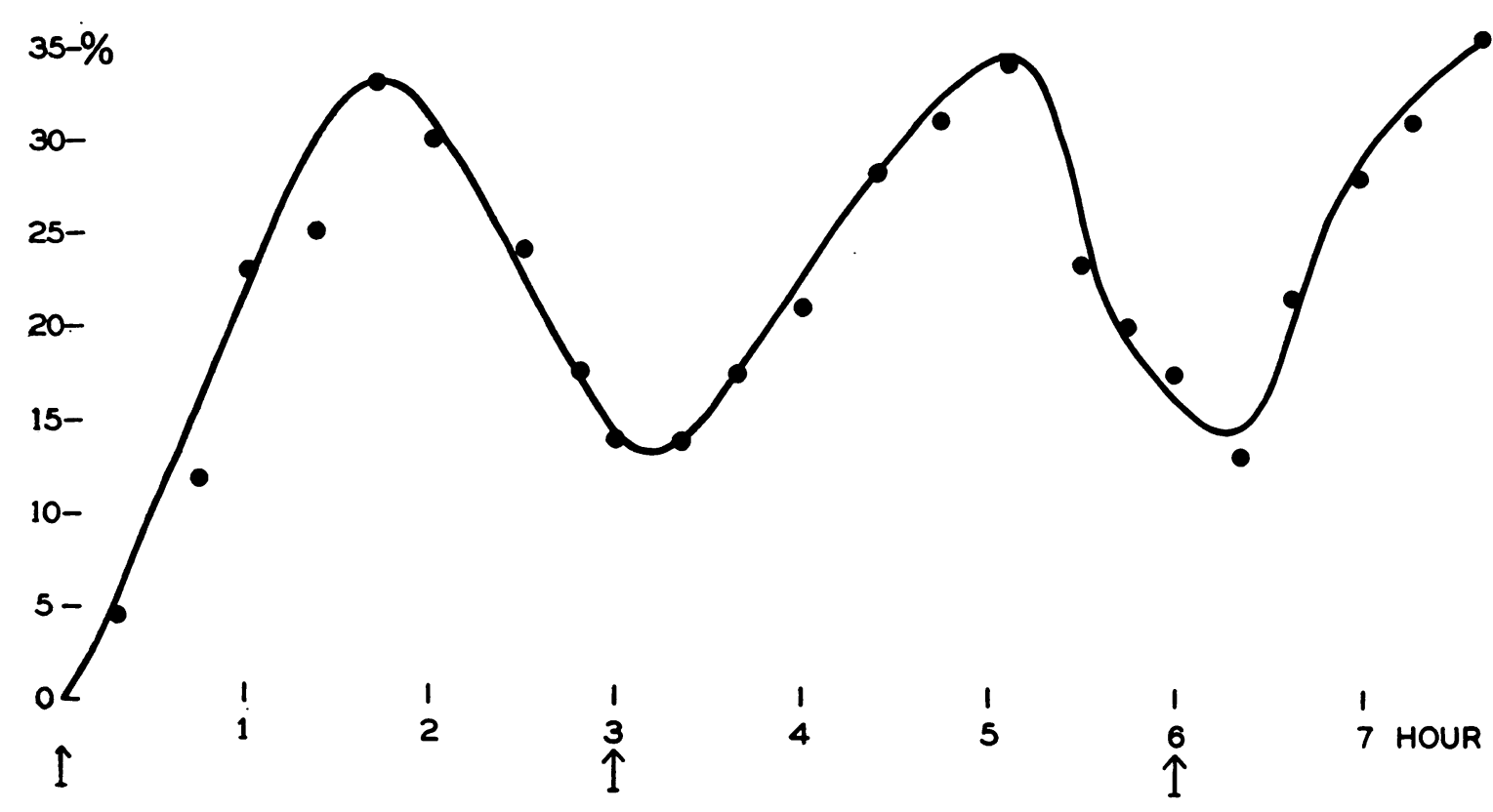

Fig. 6. The Effect on the Pain Threshold of Repeated Ingestions of Acetylsalicylic Actd 0.6 Gram at 3-HOUR INTERVALS

Each point represents the average of the threshold levels of two subjects. The arrows indicate the time of ingestion of the acetylsalicyclic acid.

tions of acetylsalicylic acid, since the essential elimination of this agent is very rapid. Secondly, Figures 5 and 6 demonstrate that in no case is a threshold-raising effect of much more than 35 per cent above the control level realized. This gives added support to the conception of a saturation amount; that is, effective addition of thresholdraising action occurs only for quantities less than the saturation amount of 0.3 gram. Similar "saturation effects" were observed in studies on codeine phosphate (1).

Psychological and other effects. Observations. Acetylsalicylic acid in amounts as small as 0.18 gram had a mild sedative effect as well as pain threshold-raising action. The sedative effect remained slight even with amounts ten times larger, i.e. 1.8 grams. The three subjects experienced mild relaxation and lethargy. Little or no effect on anxiety or tension was noted except that restlessness was reduced. There were no induced feelings of contentment, euphoria, or apathy. No untoward effects resulted except slight burning sensations in the epigastrium after larger amounts, and slight difficulties in attention and concentration after repeated administrations of the agent at 2 -hour intervals.

Comment. After the administration of acetylsalicylic acid the subject, during successive threshold readings, became aware of a change in the character of the stimulus. The sensation of heat which preceded the onset of pain became relatively more intense and it was with surprise that no pain was experienced. The probable explanation of this phenomenon is that the threshold of heat is actually lowered by acetylsalicylic acid (21). No such experience followed the administration of opiates.

The effect of pain on the action of acetylsalicylic acid

It has previously been shown that the thresholdraising action of the opiates is considerably modi- 


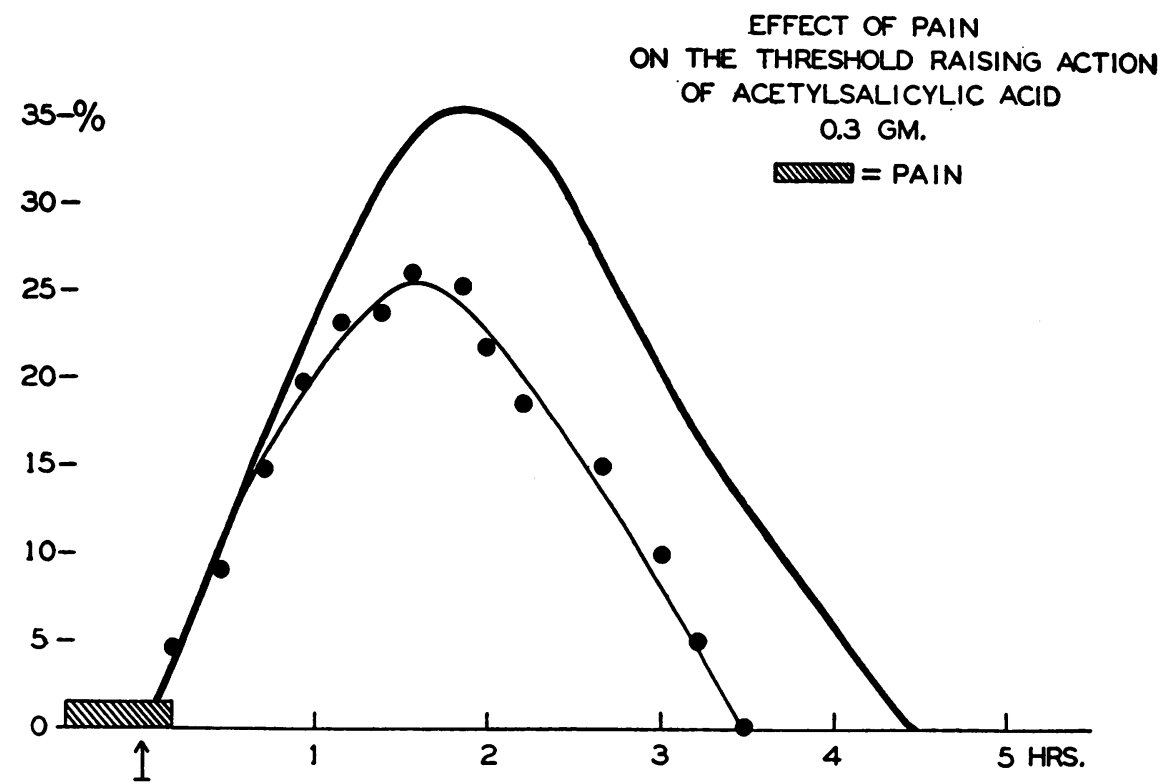

Fig. 7. The Effect of Sustained Pain for 40 Minutes on the Pain Thresholdraising Properties of Acetylsalicylic Acid (0.3 Gram)

The heavy black line represents the pain threshold-raising effect of 0.3 gram acetylsalicylic acid in three subjects without pain. The light line represents the pain threshold-raising effect of 0.3 gram acetylsalicylic acid when given 27 minutes after the beginning of pain. Each curve represents the average of the threshold levels in two subjects. The arrow indicates the time of administration. The IIIIII indicates the duration of the pain.

fied by pain introduced just before or soon after their administration (1). Indeed, pain of moderate intensity of 40 minutes' duration seriously reduces the threshold-raising action of 0.015 gram of morphine. It has been pointed out that the therapeutic usefulness of the opiates, therefore, depends largely upon qualities other than those which raise the pain threshold (1).

Acetylsalicylic acid differs from the opiates also in this regard.

Method. Experiments using induced pain, identical with those done with the opiates, were repeated with acetylsalicylic acid. A sphygmomanometer cuff placed about the arm was inflated to $220 \mathrm{~mm}$. $\mathrm{Hg}$ and then kept in place for 40 minutes. During this period there gradually developed increasingly intense pain. Ten to $15 \mathrm{~min}$ utes before the termination of the pain period, acetylsalicylic acid was administered orally in amounts of 0.3 gram to 0.9 gram.

Observations. Pain experienced during the first part of the action of the acetylsalicylic acid reduced the threshold-raising effect and the dura- tion of action of the agent in three experiments representing seven observations. In Figure 7 is shown the effect of pain on the threshold-raising action of $0.3 \mathrm{gram}$. In one experiment $0.9 \mathrm{gram}$ was taken instead of 0.3 gram. The thresholdraising action of both amounts of the drug was affected to about the same degree by the pain.

Comment. Without a large series of experiments performed under various circumstances, no final statement of the influence of pain on the effects of acetylsalicylic acid can be made, but presumably pain may cause the agent to lose about a quarter of its effectiveness. The amount of effect of the pain probably depends on many factors, including duration and intensity of pain, but these have not been analyzed. The effect of pain on the action of acetylsalicylic acid is in striking contrast to what occurs when pain precedes or overlaps the administration of morphine (1). Here most of the threshold-raising effect may be eliminated by an intensity and duration of pain no greater than that employed here. 


\section{Acetylsalicylic acid as a therapeutic agent}

The ability to raise the pain threshold coupled with relatively minor effects on mood or mentation gives acetylsalicylic acid, and presumably other salicylates, a unique position in therapy. It may be administered in relatively large amounts over long periods with slight danger of dependence.

Acetylsalicylic acid has been found to be especially useful in pains of low intensity, not only when circumscribed but also when widespread in origin. It is not the total distress experienced by the patient, but the intensity of the pain which determines the therapeutic effectiveness of a given threshold-raising agent. If the pain is of an intensity that cannot be abolished or greatly reduced by the threshold-raising effect of the agent, then no matter how limited the area or distribution is, no amount of this substance will stop the pain. For example, the intense pain associated with coronary occlusion, though it emanates from a very limited area, is not eliminated by acetylsalicylic acid. On the other hand, the relatively lowgrade pain of rheumatic fever, though very widespread in origin, is dramatically abolished.

These facts are compatible with the evidence concerning non-spatial-summation of pain formulated elsewhere (21). Thus the total intensity of several areas of different intensities of pain is equal, not to their sum, but merely to the intensity of the severest pain. It requires no more acetylsalicylic acid to abolish a widespread area of lowgrade pain than it does to abolish a very small area of pain of the same intensity.

Apparently a total of 3.6 grams per day taken in divided doses of 0.3 gram every 2 hours is more effective than a total of 4.8 grams per day taken in divided doses of 0.6 gram every 3 hours. Since the actions of 0.3 gram and 0.9 gram amounts of acetylsalicylic acid were about equally affected by pain, there is little evidence to suggest that the ingestion of larger amounts would be more effective than the 0.3 gram amount in the presence of pain.

There is the possibility that quantities of acetylsalicylic acid greater than those necessary to raise the pain threshold the maximal amount may be required to attain other useful actions of this agent.

\section{Acetylsalicylic acid in combination with other agents}

Three experiments, representing 8 series of observations, were done with combinations of codeine phosphate and acetylsalicylic acid. First, a combination of amounts of these agents having about the same threshold-raising effect was administered (1). Acetylsalicylic acid was taken by mouth in 0.3 gram amounts and 30 minutes later 0.03 gram of codeine phosphate was given hypodermically.

The threshold-raising effect of this salicylate and codeine combination under these conditions was no greater than the action of each taken separately (Figure 8a). The sedative and mood-changing effects of the codeine were well defined.

In another experiment, 0.6 gram of acetylsalicylic acid was taken by mouth, and one hour later 0.03 gram of codeine phosphate was injected intramuscularly. A threshold-raising effect of approximately 35 per cent resulted, showing that the addition of codeine had no further thresholdraising action (Figure $8 b$ ).

To ascertain whether the threshold-raising effect of 0.06 gram of codeine could be raised above its saturation level of 45 to 50 per cent above threshold level, 0.9 gram of acetylsalicylic acid was combined with codeine. The codeine was administered intramuscularly 27 minutes after ingestion of the acetylsalicylic acid. The combination had a threshold-raising effect but slightly different from that of 0.06 gram of codeine alone (Figure $8 c)$.

The combination of acetylsalicylic acid and calcium was investigated. Three-tenths gram of acetylsalicylic acid and 2 grams of calcium gluconate were taken by mouth. The threshold-raising effect and duration of action that resulted from the combination were no greater than that obtained from 0.3 gram of acetylsalicylic acid alone.

Comment. It has thus been shown that there is no addition of pain threshold-raising effect when codeine and acetylsalicylic acid are taken together in various amounts.

Nevertheless, the therapeutic usefulness of such a combination may not be waived. Codeine, as a typical opiate, has two important actions (1): (1) It impedes to a greater or lesser degree the perception of pain; and (2) it detaches the perception of pain from the fight-flight-anxiety reaction so 


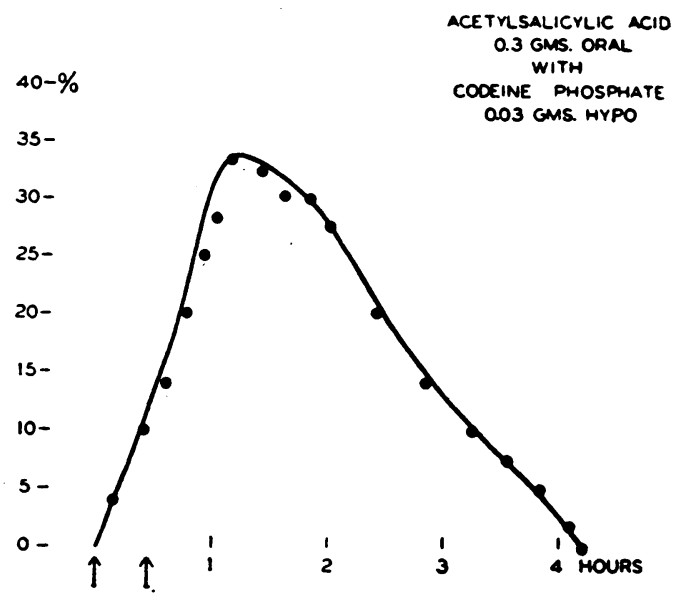

Fig. 8a. The Average Pain Threshold Elevation for Three Subjects Resulting from the Administration of 0.3 Gram Acetylsalicylic Acid (Oral) and 0.03 Gram Codeine Phosphate (Intramusculr) 27 Minutes Later

The arrows indicate the administration of the acetylsalicylic acid first, followed by administration of the codeine phosphate.

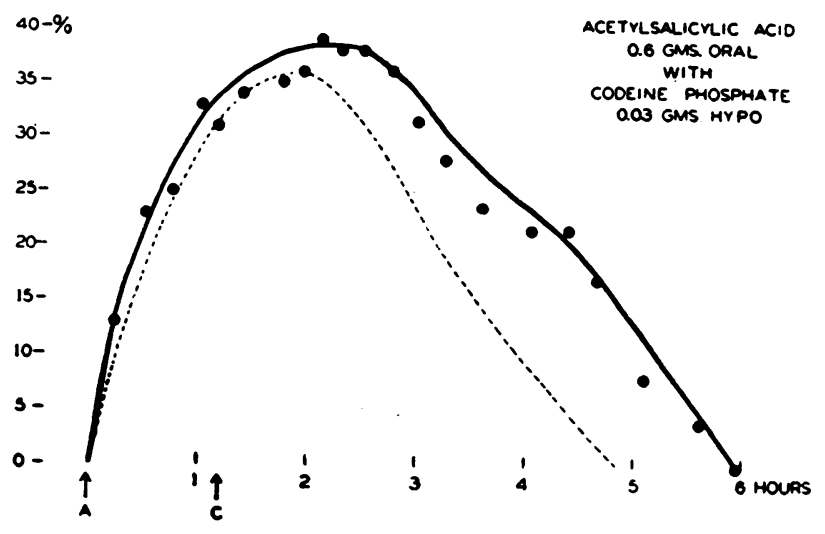

Fig. 8b. The Agerage Pain Threshold Elevation for Three Subjects Resulting from the Administration of 0.6 Gram Acetylsalicylic Acid (Oral) and 0.03 Gram Codeine Phosphate 72 Minutes Later (Intramuscular)

The arrow $A$ indicates the administration of the acetylsalicylic acid and the arrow $C$, the codeine phosphate. The dashed line indicates the threshold-raising action of $\mathbf{0 . 6} \mathrm{gram}$ acetylsalicylic acid alone.

closely attached to it. It is this aspect of opiate action, most evident in morphine, which is the common denominator of almost everyone's experience with these agents. The pain sensation is perceived and is recognized as pain with no difficulty, but as a result of the opiate action there does not follow thereon the usual reaction pattern to pain. In short, the opiates dissociate pain perception from the reaction pattern. In the presence of pain the threshold-raising effect of codeine may be eliminated, whereas the effect of acetylsalicylic acid on pain threshold is relatively little impaired. On the other hand, the effects of codeine on mood and mentation for the most part persist. The combination of the sedative and mood-changing effect of the codeine with the more 


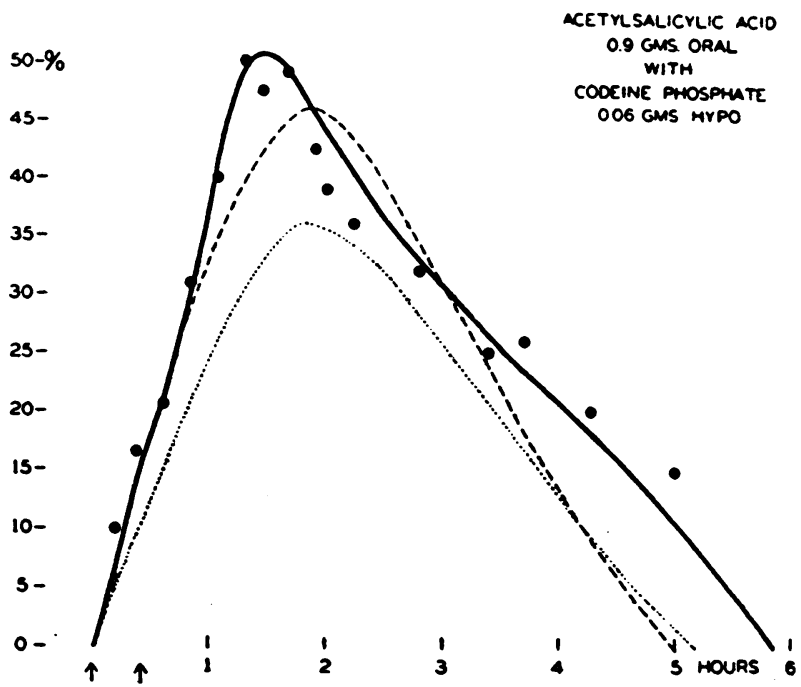

Fig. 8c. The Average Pain Threshold Elevation for Three Subjects Resulting from the Administration of 0.9 Gram Acetylsalicylic Actd (Oral) and 0.06 Gram Codeine Phosphate (Intramuscular) 25 Minutes Later

The dashed line represents the pain threshold elevation after 0.06 gram codeine phosphate alone. The dotted line represents the pain threshold elevation after 0.9 gram acetylsalicylic acid alone.

$$
\begin{array}{cc}
35-\% & \text { ACETANILID } \\
0.3 \mathrm{GM} .
\end{array}
$$

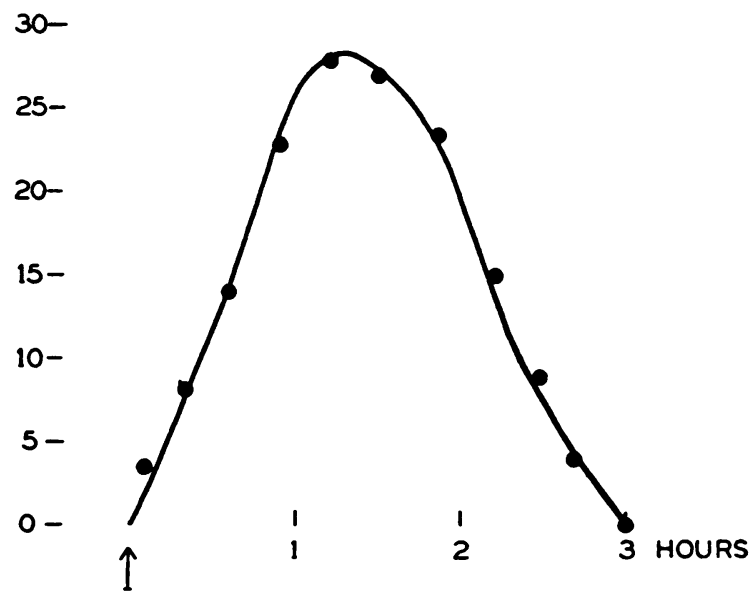

Fig. 9. The Average Pain Threshold Elevation for Three Subjects Resulting from the Administration of 0.3 Gram Acetanilid

The arrow indicates the time of administration of the acetanilid. 
stable pain threshold-raising effects of the salicylates lends a therapeutic usefulness when the two aforementioned effects are desirable. It is evident, however, that as regards pain thresholdraising effects no addition accrues from this combination.

\section{Acetanilid}

Five experiments were done with 0.3 gram of acetanilid. A total of 12 series of observations was thus available for analysis (Figure 9). The height and duration of the threshold-raising effect were of the same order as that of acetylsalicylic acid. Relaxation, drowsiness and difficulty in mentation were noted, and concentration, retention and attention were all slightly impaired. Restlessness was allayed and even anxiety was diminished, but there was no euphoria.

Effect of pain on the action of acetanilid. As in the case of acetylsalicylic acid, the thresholdraising effect and duration of action were both disturbed if the initial action of the agent was coupled with pain (Figure 10). Here, too, however, the destructive action of the pain was relatively slight.

\section{Acetophenetidin}

Two experiments with 0.3 gram of acetophenetidin representing 6 series of observations were made (Figure 11). Psychological effects from acetophenetidin were more pronounced than after acetylsalicylic acid and similar to those produced by acetanilid.

Comment. It is possible that these psychological effects of acetanilid and acetophenetidin coupled with their threshold-raising action are responsible for the popularity of these agents as headache remedies, especially where tension or anxiety is dominant.

\section{Aminopyrine}

Aminopyrine was given in 0.3 gram amounts in one experiment representing 3 series of observations. The maximum threshold-raising effect averaged about 31 per cent above the control level
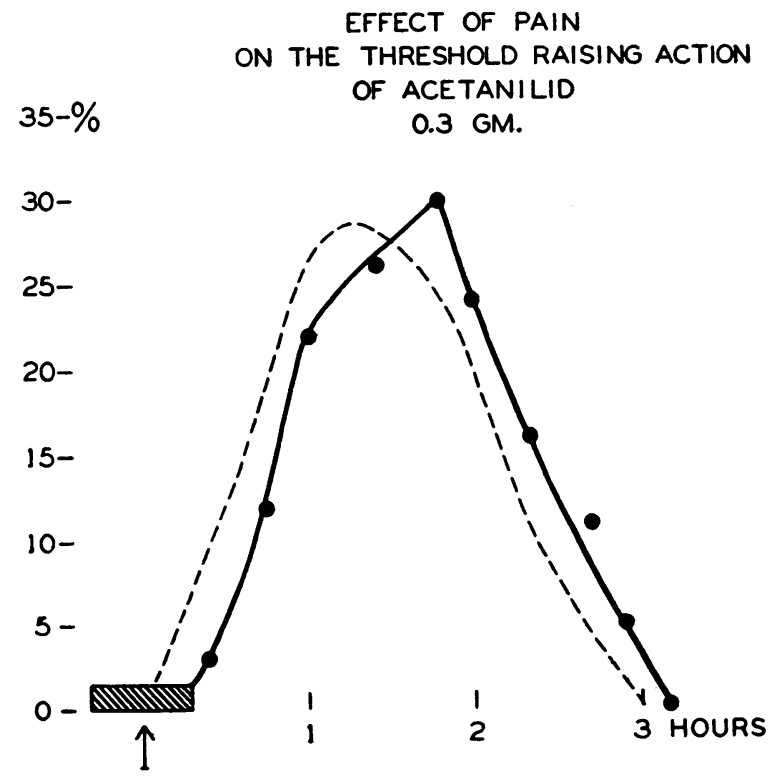

Fig. 10. The Effect of Sustained Pain (40 Minutes) on the Pain Threshold-raising Properties of ACetanilid

The dashed line represents the pain threshold-raising effect of 0.3 gram acetanilid without pain. The solid line represents the effect with pain (average for three subjects). The arrow indicates the time of oral administration of the acetanilid. The VIIIII indicates the duration of the pain. 
ACETOPHENETIDIN

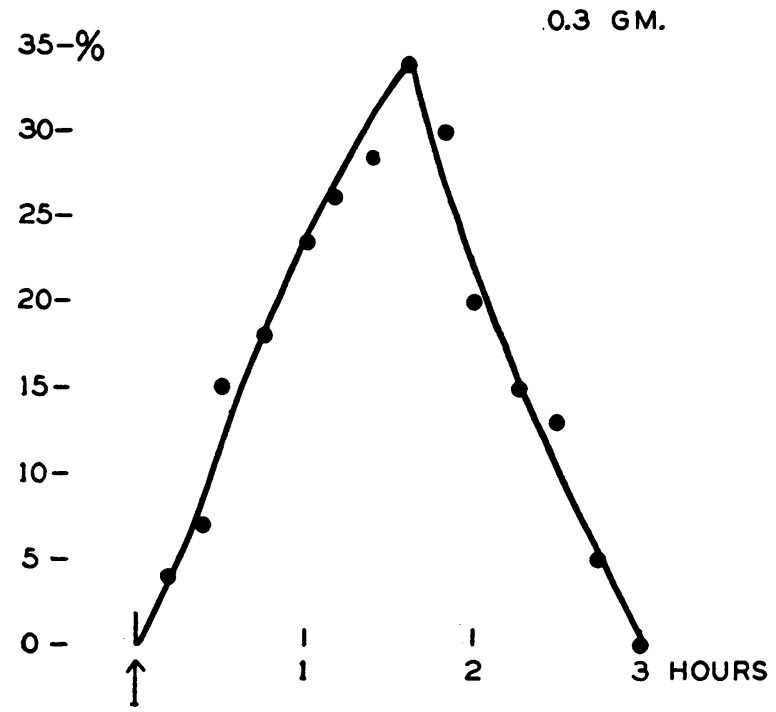

Fig. 11. The Average Pain Threshold Elevation for Three Subjects Resulting from the AdministraTION OF 0.3 GRAM ACETOPHENETIDIN

The arrow indicates the time of oral administration.

$45-\%$

ETHYL ALCOHOL 30 CC. AND $60 \mathrm{CC}$

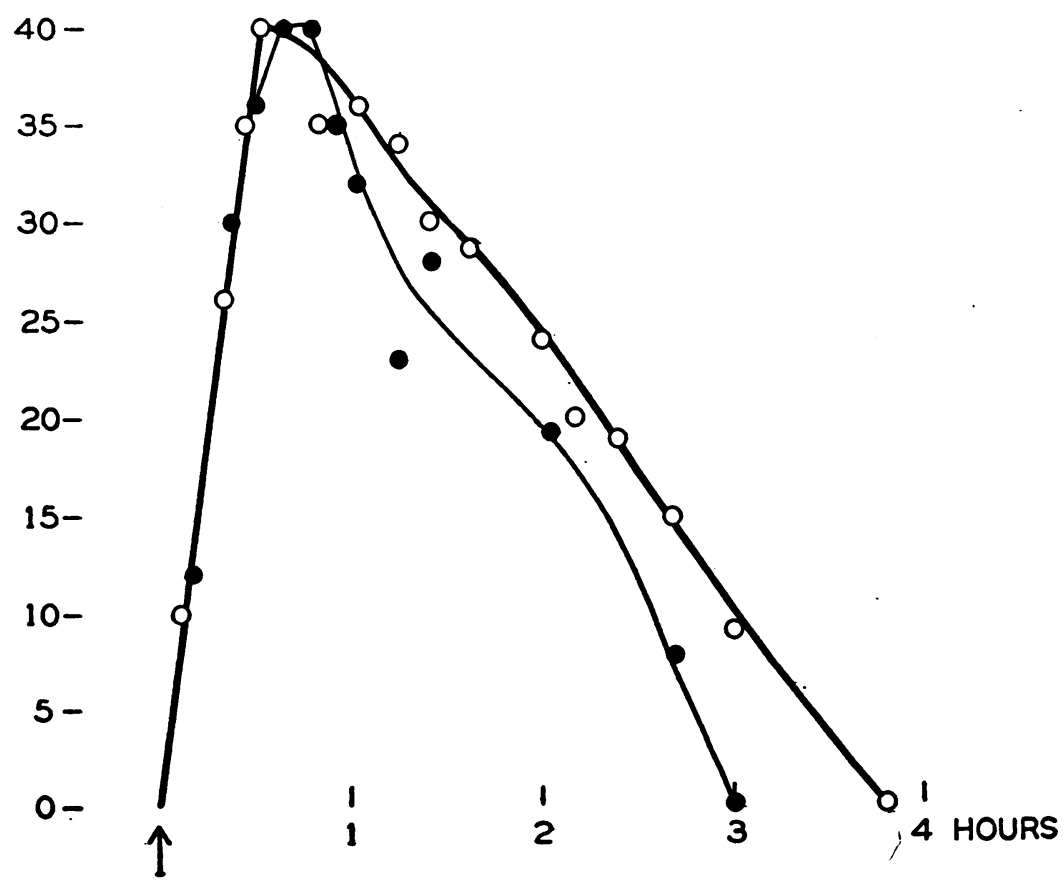

Fig. 12. The Pain Threshold Elevation Resulting from the Oral Administration of $30 \mathrm{cc}$. ANd $60 \mathrm{cc}$. of Ethyl Alcohol, 95 Per Cent

Each solid dot represents the average of the threshold levels in three subjects after $30 \mathrm{cc}$. of alcohol; the hollow dots, the same, after $60 \mathrm{cc}$. of alcohol. The arrow indicates the time of administration of the alcohol. 


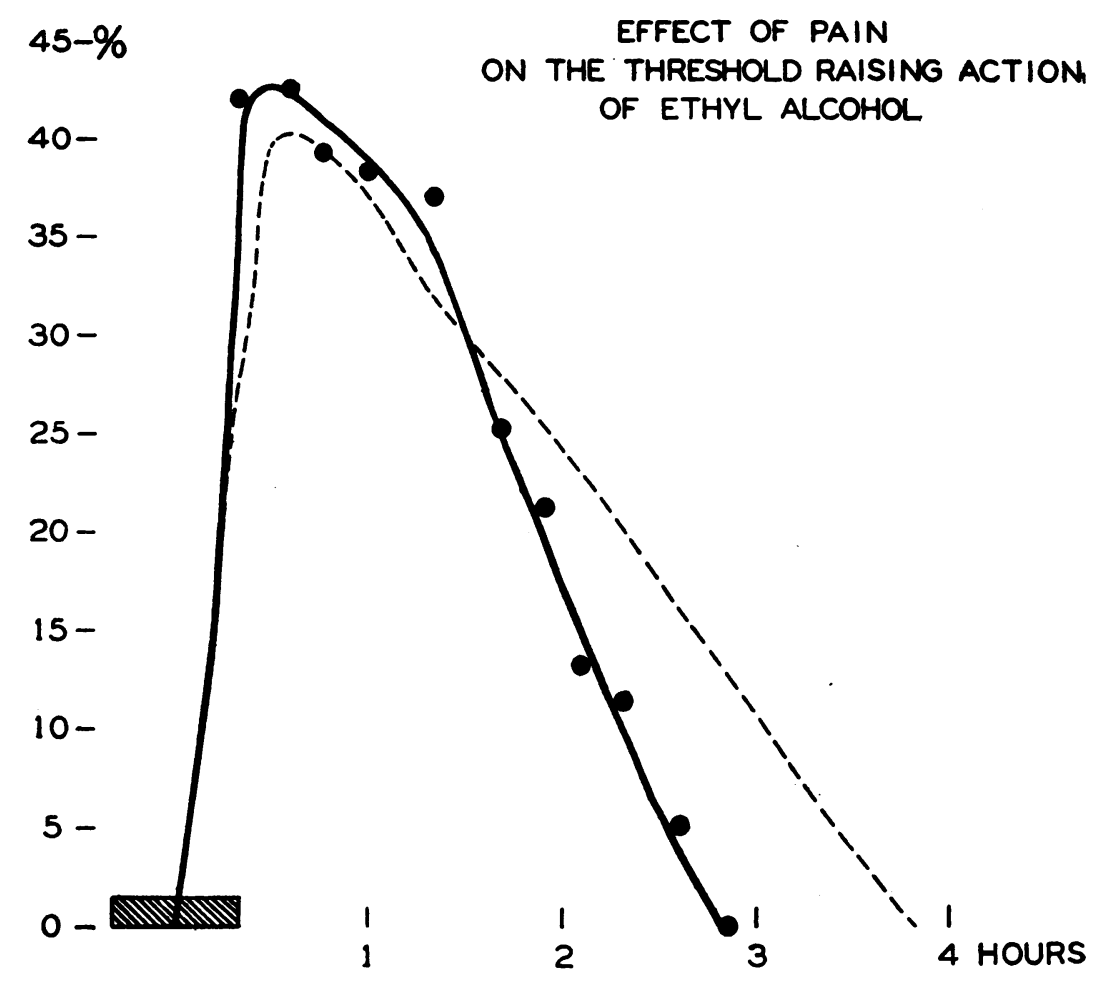

Fig. 13. The Efrect of Sustained Pain (40 Minutes) on the Pain Threshold-raising Properties of Ethyl Alcohol (60 cc., 95 Per Cent) Administered 20 Minutes After the Beginning of Pain (Solid Line), Average of Three Subjects

The dashed line represents the pain threshold-raising effect of $60 \mathrm{cc}$. of ethyl alcohol in three subjects without pain. The IIIIII indicates the duration of the pain.

and was attained about one hour after ingestion. The threshold remained elevated at or near the maximum for 30 minutes. The threshold was elevated above the control level for about 2 hours. With the exception of very slight relaxation, no other effects were noted.

\section{Ethyl alcohol}

Four experiments representing a total of 12 series of observations were done. Two of these were with amounts of $30 \mathrm{cc}$. of 95 per cent alcohol, and two with $60 \mathrm{cc}$. (Figure 12). The alcohol was ingested about 3 to 5 hours after the last meal and all of it was swallowed within 2 minutes. The alcohol was diluted with charged water containing sugar for sweetening so that the total volume of fluid was $250 \mathrm{cc}$.

Psychological and other effects. Alcohol in these subjects produced changes important because of their effect on pain, namely, the induced feelings of relaxation, contentment, detachment, and euphoria. Also, time appreciation was altered so that standard intervals seemed shorter. Concentration, attention and retention were defective, memory for events that occurred during this phase was blurred, and restraint, judgment and discrimination were impaired. This period of euphoria lasted about an hour and was followed by one of depression and lethargy. Although the mood had changed, the defects in concentration, attention and retention persisted for another 2 hours.

The peak of the threshold-raising effect and the peak of excitement and euphoria occurred at about the same time. The period of increasing depression and lethargy was associated with fall of the pain threshold to the normal control level.

Effect of pain on the threshold-raising action of ethyl alcohol. Experiments identical with those done with the opiates, acetylsalicylic acid, and acetanilid were performed with alcohol. Pain of 
40 minutes' duration was induced by the tight sphygmomanometer cuff about the arm. The alcohol was imbibed about 20 minutes after the cuff had been inflated and when pain was already very intense. Neither the height nor duration of the threshold-raising effects of the alcohol was substantially reduced as a result of the pain (Figure 13).

The subjects were able to perceive pain of high intensity, but within 3 minutes of the time of ingestion the reaction to the pain began to change to one of detachment. The reaction to pain was altered in a manner not unlike that experienced after morphine, so that, although the subject perceived pain, he became indifferent to it. Restlessness and pacing of the floor because of the pain from the tight cuff were lessened within 5 minutes of ingestion.

Comment. Ethyl alcohol thus had a double effect not unlike morphine (1): (1) It raised the threshold in the presence or absence of pain, and (2) it changed the reaction to pain in such a way as to cause the subject to feel detached about such pain which he was perceiving at the time. Alcohol has a seeming superiority over morphine as a therapeutic agent since the latter has its threshold-raising action reduced or abolished by pain. But the overactivity and lack of restraint induced by the ethyl alcohol could be undesirable for the patient as well as for those about him.

\section{Trichlorethylene}

The most swiftly acting of the analgesic agents investigated was trichlorethylene which, when inhaled, had its maximum effect even sooner than alcohol. Two experiments representing 4 series of observations were done. One cc. of trichlorethylene (Calco Chemical Co.) was inhaled under as uniform conditions as inhalation experiments permit. The pain threshold was measured on the head in the usual manner and on the back of the hand. Identical threshold-raising results were observed. The time required to reach the maximum elevation was approximately 15 minutes. The threshold remained elevated at or near the maximum for 9 to 20 minutes, depending on the speed of inhalation, and remained above the control level for about three quarters of an hour (Figure 14). During the inhalation, the subjects

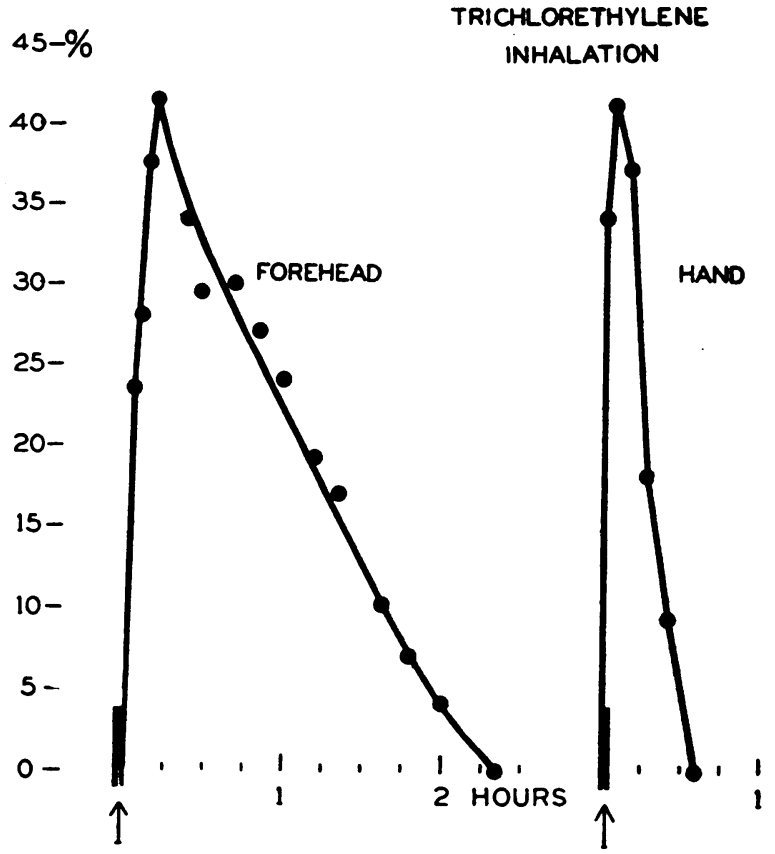

Fig. 14. The Average Pain Threshold Elevation for Three Subjects Resulting from the Administration (INHALATION) OF TRICHLORETH YLENE

Readings made on the forehead in the first experiment and on the back of the hand in the second experiment. The arrows indicate the periods (4 minutes) of inhalation of the contents of $1 \mathrm{cc}$. trichlorethylene "pearls."

experienced sensations of "light-headedness" and impending syncope. It is of interest that the threshold-raising effect was not limited to the head, but was equally great on the hand. This observation was made earlier (11) by the use of stiff hairs on pain endings in the skin.

\section{Barbiturates}

One experiment representing 3 series of observations was done with 0.5 gram of the sodium salt of $\mathrm{N}$-methylcyclohexenylmethyl barbituric acid ("Evipal" brand). This variety of barbiturate was selected because of its prompt action and elimination. By keeping the subjects awake, the threshold-raising effects due to sleep, per se, were avoided. As seen in Figure 15, an amount of barbiturate barely compatible with a waking state produced a threshold-raising effect of only 21 per cent.

Out of all proportion to the threshold-raising effect were the sedative and hypnotic effects. Within 20 minutes of ingestion the subjects be- 
came profoundly relaxed, lethargic and unsteady on their feet. They were slightly loquacious. Concentration, attention and retention were seriously disturbed and manipulative skill was much reduced. Acts requiring discrimination were poorly done. The pain threshold-raising effects of this barbiturate in combination with acetanilid and acetylsalicylic acid are discussed below.

Comment. Under the circumstances of this experiment, this barbiturate had relatively slight analgesic action and, since it is in no way unrepresentative, all barbiturates probably behave somewhat similarly. However, if sleep is induced, an entirely new set of analgesic factors may be introduced. Sleep as a threshold-raising factor has not been fully studied, but initial experiments indicate considerable threshold elevation during sleep. When consciousness is maintained, barbiturates have poor pain threshold-raising action. Eddy previously came to a similar conclusion (6).

\section{Quinine}

In one experiment representing 3 series of observations, 0.3 gram quinine sulphate taken by mouth did not raise the pain threshold above the control level.

\section{Caffeine}

Because of its frequent use in so-called " headache mixtures," as well as other combinations of analgesics, the effect of caffeine salts on the pain threshold was ascertained. In one experiment representing 3 series of observations, caffeine sodiobenzoate in 0.5 gram (intramuscular) amounts had no measurable action on the threshold. Ten minutes after the administration of the caffeine the subjects began to experience a series of changes, only a few of which are relevant to this discussion. Significant were the feelings of alertness, well-being, and improved general effectiveness.

It is evident from these data that caffeine has no threshold-raising action. However, caffeine when taken by mouth has a slight vasoconstrictor action on the cranial arteries 23 . and may thus be a factor in relieving certain headaches in a manner akin to, but far less effectively than, ergotamine tartrate $(22,23)$. The notion that it improves circulation and offsets the detrimental action of the pyrazoline compounds is little supported by bedside or experimental evidence. The mild, induced exhilaration above described may engender this impression.

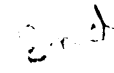

\section{N-METHYLCYCLOHEXENYLMETHYL \\ BARBITURIC ACID \\ (SODIUM SALT) \\ $0.5 \mathrm{GM}$.}

$30-\%$

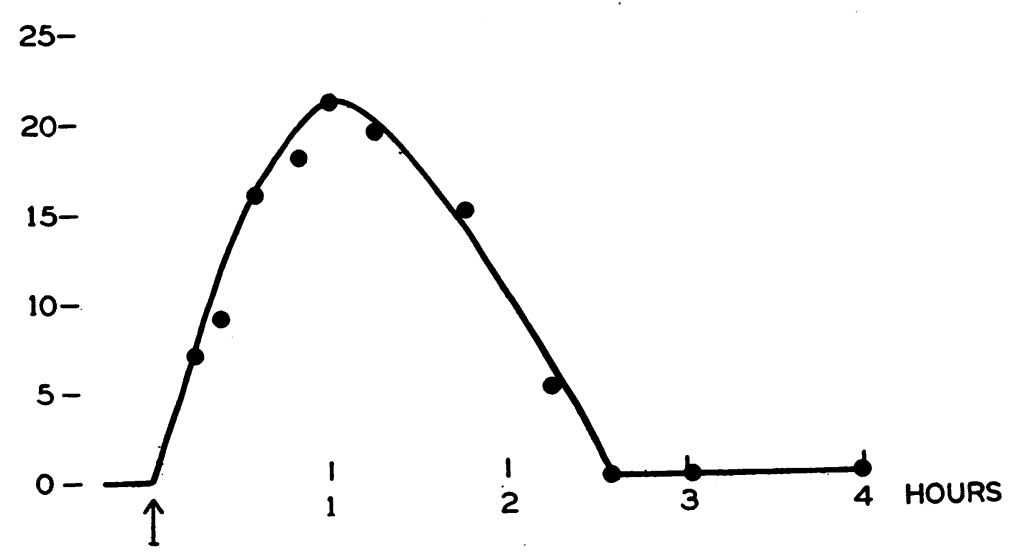

Fig. 15. The Average Pain Threshold Elevation for Three Subjects Resulting from the Oral Administration of 0.5 Gram N-MethylcycloheXeNYLMETHYL Barbituric Acid-Sodium Salt

The arrow indicates the time of administration of the agent. 


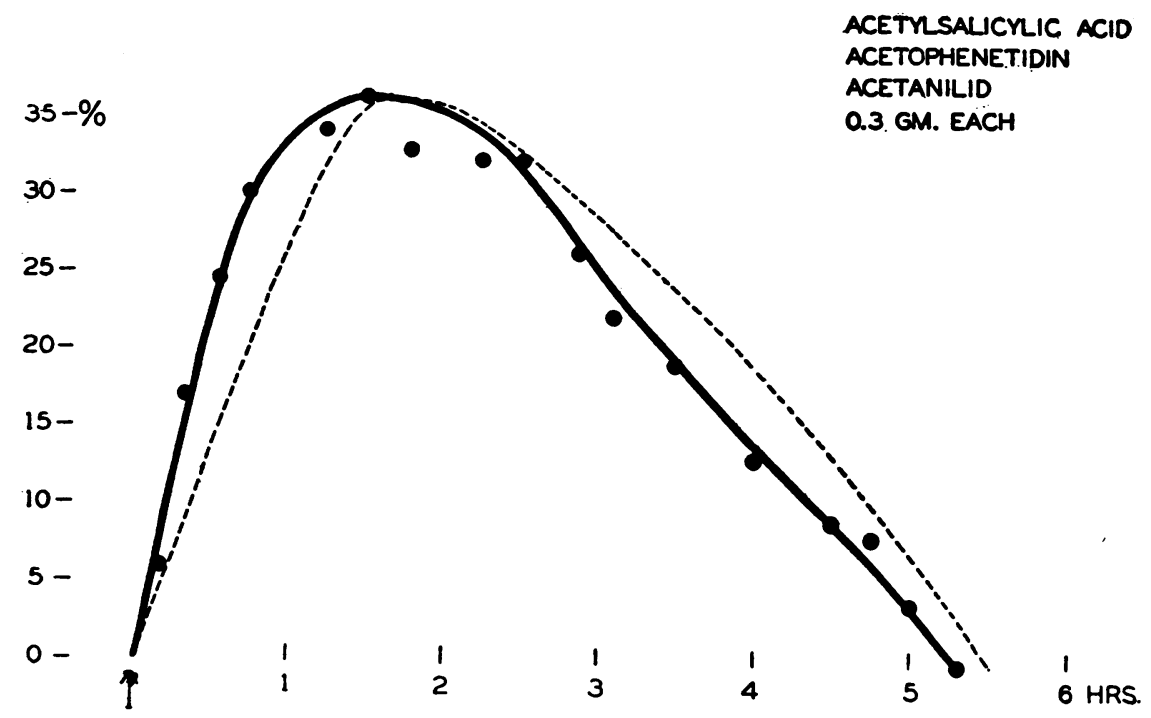

Fig. 16a. The Average Pain Threshold Elevation for Three Subjects Resulting from the Administration of the Combination of Acetylsalicylic Acid, Acetophenetidin and Acetanilid, 0.3 Gram Each (Solid Line)

The dashed line represents the pain threshold elevation resulting from the administration of 0.9 gram acetylsalicylic acid. The arrow indicates the time of oral administration of the agents.

\section{Ergotamine tartrate}

The dramatic termination of migraine headache by $0.5 \mathrm{mgm}$. injections of ergotamine tartrate aroused curiosity concerning the nature of the analgesic action of this agent. It has been demonstrated (22) that the decline in intensity of the headache is coincident with the decrease in amplitude of pulsations of the cranial arteries, chiefly the branches of the external carotid arteries. It was inferred that the contraction of dilated arteries reduced the deformity of pain end organs about these arteries and so terminated the headache.

In one experiment representing 3 series of observations, ergotamine tartrate $(0.5 \mathrm{mgm}$. intramuscular) did not raise the pain threshold. It induced feelings of prostration with nausea. Therefore, such effect as this agent has in diminishing headache cannot be attributed to a pain threshold-raising action.

\section{Other combinations}

It is important in appraising the action of combinations to separate clearly the resultant pain threshold-raising action of a combination from other desirable effects. It is readily appreciated that one may wish to combine an agent with good pain threshold-raising action with one having suitable sedative and hypnotic action, as well as other effects on mood and mentation.

Observations. The combination of acetophenetidin, acetanilid, and acetylsalicylic acid each in $\mathbf{0 . 3}$ gram amounts was tested once, representing 3 series of observations (Figure 16a). The combination had no greater threshold-raising action than an equivalent weight (0.9 gram) of acetylsalicylic acid. However, the sedative and hypnotic effect of the combination was far greater than the latter.

The threshold-raising effect of the well-known combination of caffeine citrate, 0.15 gram; acetophenetidin, 0.15 gram; acetylsalicylic acid, 0.15 gram, was investigated in one experiment, representing 3 series of observations. Two tablets, each containing the above mixture and amounts, were taken. The threshold-raising effect of the combination was no greater than an equal weight ( 0.9 gram) of acetylsalicylic acid. However, this combination, as well as the previous one, presented effects which were worthy of note. Relaxation, lethargy, and freedom from restlessness were well defined. It appeared to the observers that the 
sedative effects were summative even though the threshold-raising effects were not.

The sodium salt of $\mathrm{N}$-methylcyclohexenylmethyl barbituric acid ("Evipal") in 0.5 gram amounts was administered orally in combination with 0.3 gram of acetanilid. One experiment, representing 3 series of observations, was performed. No increase in the pain threshold-raising effect of acetanilid was observed. However, effects other than threshold-raising were important. Unsteadiness of gait, difficulty with skilled manual movements, difficulty in mentation, and barely controllable lethargy were noted. Diplopia was present. Again, the opinion shared by the three observers was that the sedative and hypnotic effects were summative.

A combination of a barbiturate and acetylsalicylic acid was also investigated (Figure 16b). The pain threshold-raising effect of 0.5 gram of $\mathrm{N}$-methylcyclohexenylmethyl and 0.3 gram acetylsalicylic acid was ascertained in one experiment, representing 3 series of observations. The threshold-raising effect was no greater than that from 0.3 gram acetylsalicylic acid alone. The total action as expressed in hours per cent was not increased. However, other effects were greatly increased over those of acetylsalicylic acid alone and even more evident than after the barbiturate alone. Diplopia, unsteadiness of gait, diffculty in mentation and profound lethargy were. noteworthy.

Comment. It may be said, in general, of the combinations studied that the pain thresholdraising effect of a combination is no greater than that of its most effective ingredient, but that the sedative and hypnotic effects, as well as motility disturbances, may be summative. There may be valid grounds for giving agents such as codeine and barbiturates with such substances as acetylsalicylic acid, acetophenetidin and acetanilid, if one desires to achieve additive mood and mentation effects with antipyretic and stable threshold-raising effects.

\section{SUMMARY AND CONCLUSIONS}

1. Quantitative measurements of the pain threshold were made by irradiating 3.5 square centimeters of skin surface for 3 seconds. The intensity of radiation which barely evoked pain was denoted as the pain threshold. The thresholdraising action of various non-opiate analgesic

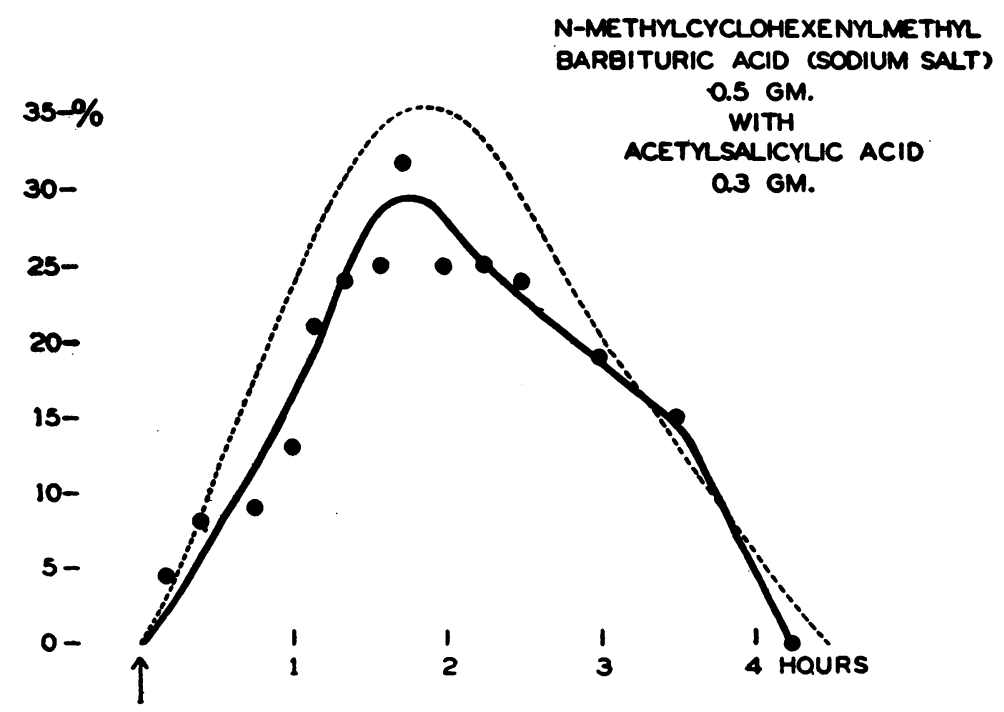

Fig. 16b. The Average Pain Threshold Elevation for Three Subjects (Solid Line) Resulting from the Administration of the Combination of N-Methylcyclohexenylmethyl Barbituric AcidSodium Salt (0.5 Gram) with Acetylsalicylic Acid (0.3 Gram)

The dashed line represents the effect of 0.3 gram acetylsalicylic acid alone. 
agents was then ascertained in terms of the normal threshold.

2. Acetylsalicylic acid (oral) in quantities from 0.03 gram to 1.8 grams was thus assayed. The minimum effective quantity of this agent is 0.06 gram ( $0.9 \mathrm{mgm}$. per kilo body weight). The "saturation" quantity or the smallest amount with which the highest threshold-raising effect was attained was 0.3 gram. The highest thresholdraising effect of which the agent was capable was approximately 35 per cent above the control threshold, and the maximum threshold-raising effect for quantities of acetylsalicylic acid, in amounts from 0.06 gram to 1.8 grams, was attained in approximately 50 to 100 minutes.

3. The time-action curves of threshold-raising effect for acetylsalicylic acid revealed that essential elimination increased at a constant rate with quantities up to 0.3 gram. However, with larger quantities of the agent, there was acceleration of the essential elimination rate so that duration of effect with 0.9 gram or 1.8 grams differed but slightly.

4. The pain threshold-raising action of 0.3 gram, respectively, of acetanilid, acetophenetidin and aminopyrine was measured. In these amounts these agents had time-action curves similar to that obtained with 0.3 gram of acetylsalicylic acid.

5. Acetylsalicylic acid induced mild relaxation and lethargy. Acetanilid and acetophenetidin in comparable amounts induced greater relaxation and lethargy and difficulties in mentation. The therapeutic effectiveness of the latter agents rests in good part on their effects.

6. The pain threshold-raising action of 30 and $60 \mathrm{cc}$. of ethyl alcohol (oral) was measured. In these amounts the alcohol had a maximum threshold-raising action of 40 per cent above the control level. The larger amount had a longer duration but no greater threshold-raising action.

7. The pain threshold-raising action, as well as other observable effects, of acetylsalicylic acid, acetanilid, acetophenetidin and ethyl alcohol was relatively slightly reduced by pain. A uniform pain stimulus was introduced just before or during the first 60 minutes after administration of the agents. Thus, the antagonism between pain and threshold-raising action noted in the case of the opiates is less evident or absent in the case of the above-mentioned agents.

8. Some effects of alcohol were akin to those of the opiates. Of special significance in both were the emotional states referred to as freedom from anxiety and feelings of contentment and detachment. While in these states the subjects perceived pain but they were indifferent to it. Thus like the opiates but perhaps to a lesser degree, alcohol accentuates the ability to dissociate pain perception from the pattern of reaction to pain.

9. The pain threshold-raising action of $1 \mathrm{cc}$. of trichlorethylene (inhaled) was measured. It had a maximum threshold-raising action of approximately 40 per cent above the control level.

10. The pain threshold-raising action of 0.5 gram of the sodium salt of $\mathrm{N}$-methylcyclohexenylmethyl barbituric acid ("Evipal" brand) was measured. It had a maximum threshold-raising action of approximately 20 per cent above the control level and induced profound lethargy and defects in mentation.

11. Caffeine sodiobenzoate, ergotamine tartrate and quinine sulphate had no pain thresholdraising properties.

12. Various combinations of acetylsalicylic acid, codeine, acetanilid, acetophenetidin, the barbiturates and caffeine were studied. The pain threshold-raising effect of these combinations was no greater than that of their most effective ingredient. Sedative and hypnotic effects, as well as defects in motility, seemed to be summative. A combination of these agents is therapeutically valid if it aims to attain useful psychological effects coupled with pain threshold-raising action. It is not valid, however, if it be assumed that the pain threshold-raising effects of the different ingredients will summate.

\section{BIBLIOGRAPHY}

1. Wolff, H. G., Hardy, J. D., and Goodell, H., Studies on pain. Measurement of the effect of morphine, codeine and other opiates on the pain threshold and an analysis of their relation to the pain experience. J. Clin. Invest., 1940, 19, 659.

2. Martin, E. G., Grace, C. M., and McGuire, J. H., The influence of drugs on the human sensory threshold. J. Pharm. and Exper. Therap., 1915, 6, 527.

3a. Kochman, M., Alkohol, In Handbuch der experimentellen Pharmakologie, bd. 1, p. 262, J. Springer, Berlin, 1923. 
b. Kochman, M., Schlafmittel. Ibid, p. 389.

c. Ellinger, A., Aromatische Kohlenwasserstoffe, Phenole, Aromatische Säuren, Aromatische Alkohole, Aldehyde, Ketone, Chinone, Nitroverbindungen. Ibid, p. 871.

d. Rohde, E., Aromatische Monamine. Ibid, p. 1049.

e. Rohde, E., Pyrazolonabkömmlinge. Ibid, p. 1106.

4. Hale, W., and Grabfield, G. P., The action of certain depressant drugs on the sensory threshold for faradic stimulation in human subjects and the effect of tobacco smoking on this action. J. Pharmacol. and Exper. Therap., 1923, 21, 77.

5. Heinroth, H., Uber die Wirkungverschiedener Arzneimittel auf die Schmerzempfindlichkeit der Zahnpulpa. Arch. f. exper. Path. u. Pharmakol., 1926, 116, 245.

6. Eddy, N. B., Studies on hypnotics of the barbituric acid series. J. Pharmacol. and Exper. Therap., 1928, 33, 43.

7. Haffner, F., Experimentelle Prüfung schmerzstellender Mittel. Deutsch. med. Wchnschr., 1929, 55, 731.

8. Hesse, E., Zur biologischen Wertbestimmung der Analgetika und ihrer Kombinationen. Arch. f. exper. Path. u. Pharmakol., 1930, 158, 233.

9. Pohle, K., and Spieckermann, W., Vergleichende Untersuchungen über die analgetische Breite verschiedener Antipyretika bei Kombination mit Schlafmitteln. Arch. f. exper. Path. u. Pharmakol., 1931, 162, 685.

10. Starkenstein, E., Zur Methodik der Prüfung schmerzstillender Mittel im Tierversuch. Arch. f. exper. Path. u. Pharmakol., 1932, 165, 325.

11. American Dental Association, Council on Dental Therapeutics, Report on Trichlorethylene. J. Am. Dent. A., 1932, 19, 683.

12. Schmidt, H., Inaugural-Dissertation Königsberg, 1933. Quoted from Eichholtz, F., and Kullmann, F. Arch. f. exper. Path. u. Pharmakol., 1937, 184, 612.
13. Hildebrandt, F., Die Prüfung der Analgetica im Tierexperiment mittels einer neuen Methode. Arch. f. exper. Path. u. Pharmakol., 1934, 174, 405.

14. Mullin, F. J., and Luckhardt, A. B., The effect of alcohol on cutaneous tactile and pain sensitivity. Am. J. Physiol., 1934, 109, 77.

15. Gilman, A., and Barbour, H. G., Effects of phenacetin and aspirin, respectively, upon the action of phenobarbital. Proc. Soc. Exp. Biol. and Med., 1935, 32, 1634.

16. Poehls, F. H., Inaugural-Dissertation Heidelberg, 1935. Quoted from Eichholtz, F., and Kullmann, F. Arch. f. exper. Path. u. Pharmakol., 1937, 184, 612.

17. Mullin, F. J., and Luckhardt, A. B., Effects of certain analgesic drugs on cutaneous tactile and pain sensitivity. Am. J. Physiol., 1935, 113, 100.

18. Eichholtz, F., and Kullmann, F., Uber die analgetische Wirkung von Veronal, Coffein, Salicylsäure, Pyramidon, Chinin und ihren Mischungen. Arch. $f$. exper. Path. u. Pharmakol., 1937, 184, 612.

19. Mullin, F. J., and Luckhardt, A. B., Effects of certain drugs on cutaneous tactile and pain sensitivity. Arch. Internat. de Pharmacodyn. et de Thérap., 1937, 55, 112.

20. Smith, P. K., The relation of acetanilid and other drugs to analgesia in monkeys. J. Pharmacol. and Exper. Therap., 1938, 62, 467.

21. Hardy, J. D., Wolff, H. G., and Goodell, H., Studies on Pain. A new method for measuring pain threshold: Observations on spatial summation of pain. J. Clin. Invest., 1940, 19, 649.

22. Graham, J. R., and Wolff, H. G., Mechanism of migraine headache and action of ergotamine tartrate. Arch. Neurol. and Psychiat., 1938, 39, 737.

23. Sutherland, A. M., and Wolff, H. G., Experimental studies on headache: Further analysis of the mechanism of headache in migraine, hypertension and fever. Arch. Neurol. and Psychiat., 1940, 44, 929. 